\title{
8
}
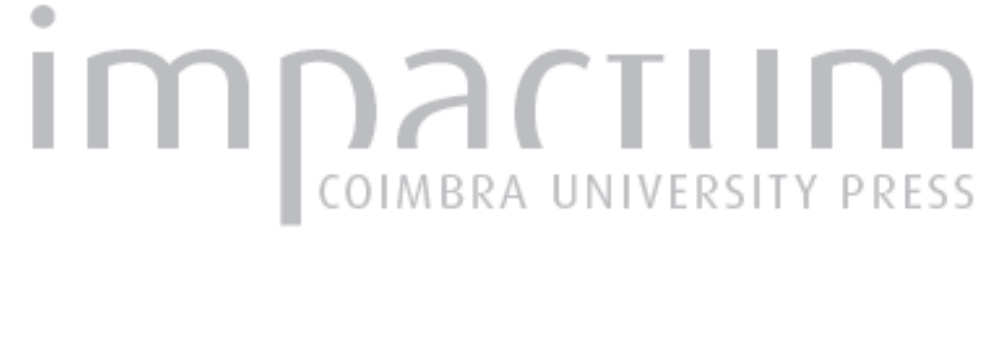

\section{Estados de consciência e níveis do eu em Plotino}

Autor(es): Brandão, Bernardo Guadalupe dos Santos Lins

Publicado por: Annablume Clássica

URL persistente:

URI:http://hdl.handle.net/10316.2/24325

DOI:

DOI:http://dx.doi.org/10.14195/1984-249X_10_8

Accessed : $\quad$ 26-Apr-2023 06:57:31

A navegação consulta e descarregamento dos títulos inseridos nas Bibliotecas Digitais UC Digitalis, UC Pombalina e UC Impactum, pressupõem a aceitação plena e sem reservas dos Termos e Condições de Uso destas Bibliotecas Digitais, disponíveis em https://digitalis.uc.pt/pt-pt/termos.

Conforme exposto nos referidos Termos e Condições de Uso, o descarregamento de títulos de acesso restrito requer uma licença válida de autorização devendo o utilizador aceder ao(s) documento(s) a partir de um endereço de IP da instituição detentora da supramencionada licença.

Ao utilizador é apenas permitido o descarregamento para uso pessoal, pelo que o emprego do(s) título(s) descarregado(s) para outro fim, designadamente comercial, carece de autorização do respetivo autor ou editor da obra.

Na medida em que todas as obras da UC Digitalis se encontram protegidas pelo Código do Direito de Autor e Direitos Conexos e demais legislação aplicável, toda a cópia, parcial ou total, deste documento, nos casos em que é legalmente admitida, deverá conter ou fazer-se acompanhar por este aviso.

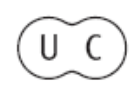



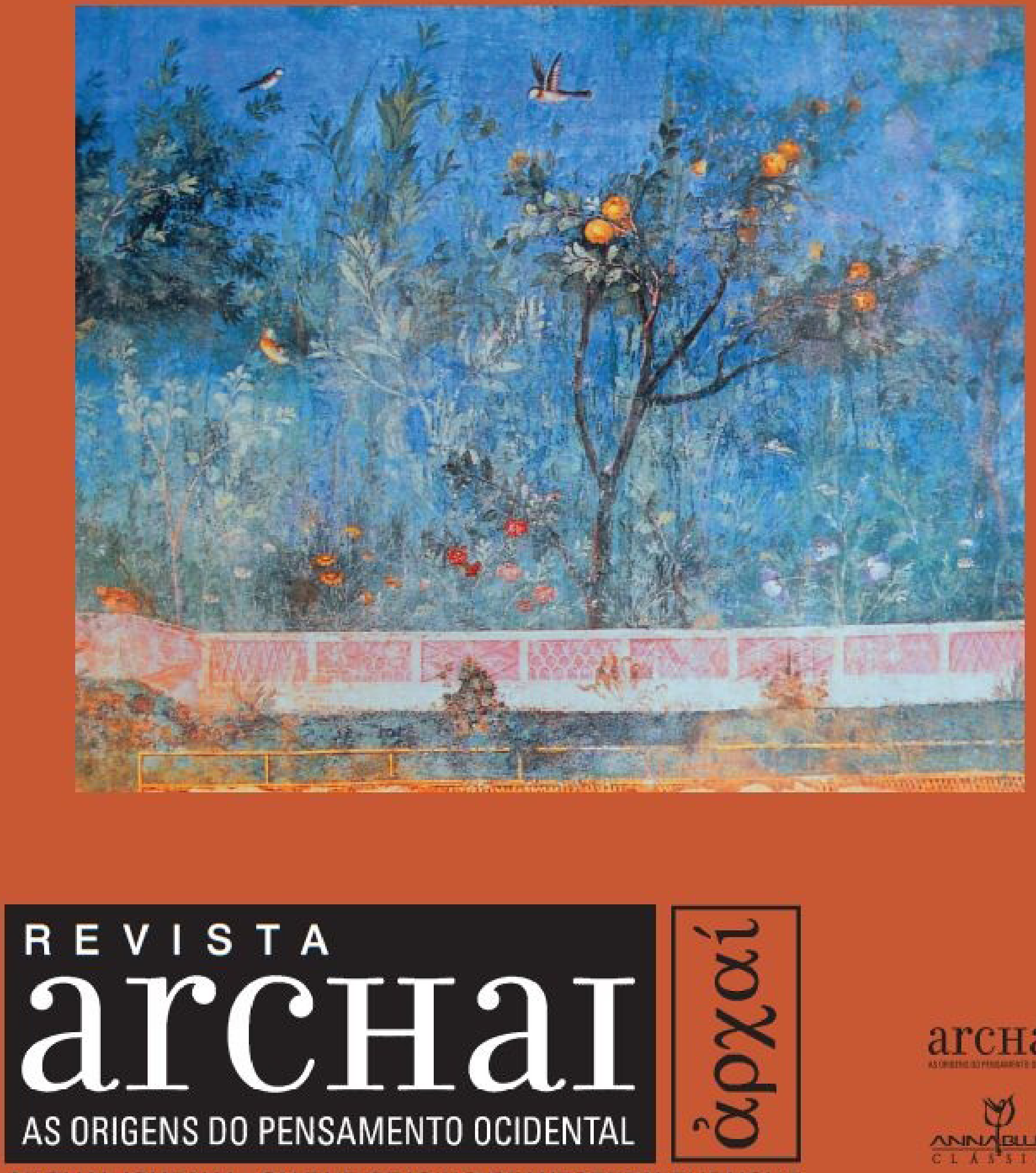

arcнаI

ARCHAI JOURNAL: ON THE ORIGINS OF WESTERN THOUGHT

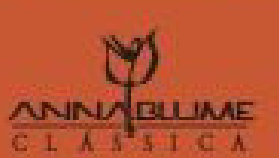




\section{ESTADOS DE CONSCIÊNCIA E NÍVEIS DO EU EM PLOTINO}

BRANDÃO, B. G. S. L. (2013). Estados de consciência e níveis do eu em Plotino. Archai, n. 10, jan-jul, p. 95-102.

RESUMO: Plotino foi um grande explorador da alma humana. Sua profunda introspecção, suas experiências supra-racionais e seu gênio filosófico tornaram-no capaz de desenvolver uma noção nova do eu, desconhecida pelos pensadores gregos anteriores, que está intimamente relacionada com as noções de parakoloúthesis, sunaisthesis e súnesis. Alguns estudiosos pensam esse eu plotiniano como uma espécie de eu móvel, mas, pelo contrário, passagens importantes das Enéadas afirmam que o eu é a alma. Tendo essas passagens em mente, nesse artigo, tento pensar o eu plotiniano não como um eu móvel, mas como uma alma que possui diferentes níveis de eu e de consciência.

PALAVRAS-CHAVE: Plotino, neoplatonismo, consciência.

ABSTRACT: Plotinus was a great explorer of human soul. His deep introspection, supra-rational experiences and philosophical genius make him able to develop a new notion of the self, unknown to the greek thinkers who came before him, closely related with the notions of parakoloúthesis, sunaisthesis and súnesis. Some scholars thinks this plotinian self as a kind of mobile self, but, on contrary, importante passages on the Enneads affirms that the self is the soul. Having this passagens in mind, in this paper, I try to think the plotinian self not as a mobile self, but as a soul who has diferente levels of self and consciousness.

KEY-WORDS: Plotinus, neoplatonismos, consciousness.
* Professor do Departamento de Letras, Universidade Federal do Paraná 1. É certo que temos que tomar cuidado ao falar de consciência em Plotino, dadas todas as conotações póscartesianas do termo tal como compreendido nos dias de hoje, mas, como ele é largamente utilizado pelos estudiosos contemporâneos das Enéadas, também o empregaremos, não deixando de notar, entretanto, que seu sentido é ligeiramente diferente do atual. Além

disso, como veremos, Plotino utilizava três palavras distintas para se referir àquilo que os estudiosos chamam de consciência. É, aliás, por isso mesmo, que podemos utilizar o termo como uma palavra genérica que, nos diversos contextos, pede certas especificações.

\section{Bernardo Guadalupe dos Santos Lins Brandão}

Plotino foi um dos grandes exploradores da alma humana na Antiguidade. Suas tendências místicas, aliadas ao gênio filosófico, permitiram a elaboração de doutrinas profundas e originais, evitando tanto o irracionalismo dos visionários quanto o lugar-comum das discussões filosóficas de seu tempo. Nas palavras de Dodds (1960, p. 5):

Essa auto-exploração é o coração do plotinismo. É nas análises do "eu" que ele faz as suas descobertas mais originais... Plotino reconhece (antecipando Leibniz) que existem sensações que não alcançam a consciência, a menos que direcionemos a atenção especialmente para elas (IV, 4, 8; V, 1, 12), e, também (antecipando Freud), que existem desejos que permanecem na parte apetitiva e são desconhecidos por nós (IV, 8, 8, 9).

Parte significativa do esforço filosófico de Plotino pode ser compreendido como a exploração dos diversos estados de consciência ${ }^{1}$ possíveis ao homem. Encontramos nas Enéadas a descrição de vários deles: a inconsciência de quem dorme ou está em coma, a consciência ordinária, a consciência que pensa sem imagens em ocasiões de grande concentração ou nos atos habituais e os estados de 
supraconsciência, na união da alma com o Intelecto ou com o Um. Esses estados estão intimamente relacionados com a jornada de ascensão da alma em direção ao Bem² ${ }^{2}$ Na medida em que o filósofo se eleva, ele experimenta uma transformações em seu modo de conhecer, que se torna cada vez mais verdadeiro, unificado e interior.

Ao mesmo tempo, descobrimos uma nova concepção do eu, desconhecida do pensamento grego anterior. As declarações dos estudiosos são abundantes a esse respeito. Bréhier (1928, p. 12), por exemplo, afirma que a noção de consciência e de eu passaram despercebidas pelos filósofos gregos e só finalmente aparecem nas investigações psicológicas de Plotino. Bumenthal (1971, p. 109), por sua vez, nota que não havia uma palavra grega que designasse a identidade pessoal até que, nas Enéadas, o pronome hemeís (nós) se transformasse em um termo técnico para designá-la. A doutrina do eu presente nas Enéadas está intimamente relacionada à exploração dos estados da alma. É a partir da constatação das múltiplas possibilidades da experiência interior que Plotino sentiu a necessidade de refletir sobre o sujeito dessas experiências. Se a jornada de ascensão ao Bem, exortada desde o primeiro de seus tratados (Enéada I, 6) é um caminho de purificação e transformação, é tarefa do filósofo descobrir quem está sendo transformado.

Mas no que consiste esse eu? Para boa parte dos comentadores, é, usando as palavras de Blumenthal (ibid, p. 110), "o foco da atividade consciente que pode mudar quando essa atividade muda". Hadot (1997, p. 23), que fala em "níveis do eu" explica: “a consciência é um ponto de vista, é um centro de perspectiva. Nosso eu, para nós, coincide com o ponto a partir do qual se abre a nós uma perspectiva sobre o mundo ou sobre nossa alma" (ibid., p. 34). Em outras palavras, trata-se de um eu móvel, determinado pelo nível de consciência de cada momento.

Essa concepção, pela afinidade com discussões contemporâneas sobre a subjetividade, tem chamado cada vez mais a atenção dos estudiosos. No entanto, a teoria do eu móvel me parece se ser mais uma projeção das questões atuais nos textos das Enéadas que uma interpretação rigorosa do pensamento de Plotino. Isso porque, como observa
O'Daly (1973, p. 49), o eu não pode ser condicionado pelo ato de consciência porque ele é o próprio veículo da consciência, o sujeito a partir do qual a consciência é o ato. Mas então, qual será a acepção da expressão tó hemeís que encontramos nos textos de Plotino? Qual a sua relação com os níveis de consciência descritos nas Enéadas?

Para respondermos a essas perguntas, é útil termos em mente a concepção plotiniana do homem. Para Plotino, o homem é um ser complexo, um "universo inteligível" (kósmos noetós) e a alma "é muitas coisas, todas as coisas, tanto as de cima quanto as de baixo, até onde vai a vida" ${ }^{3}$. Por um lado, a alma humana está ligada ao mundo sensivel através do composto formado pelo corpo caracterizado ${ }^{4}$ e por uma espécie de luz emitida (En. I, 1, 7, 1-5) por ela, que Plotino chama, em uma série de textos, de “imagem da alma" ${ }^{5}$. Por outro, como na metafísica das Enéadas, os níveis de realidade inferiores são dependentes e contínuos aos superiores, a alma também está ligada a o Intelecto e ao Um.

Portanto, podemos falar que a alma se relaciona com todas as esferas da realidade, apresentando, de acordo com Igal, cinco níveis psíquicos: “vegetativo, sensitivo, racional, noético e supranoético" ${ }^{{ }^{6}}$. Nesse panorama, o nível racional é o "especificamente humano" ${ }^{7}$. É por isso que Plotino, em VI, 4, 14, 16-25 fala de dois homens:

E nós (hemeís), o que somos nós? Somos aquele ou somos o que se aproximou e surgiu no tempo? $\mathrm{Na}$ verdade, antes de acontecer o nascimento, estávamos lá [no inteligível], sendo outros homens e, alguns, também deuses: almas puras e intelectos unidos à essência total, partes do inteligível, sem separação, sem divisão, mas sendo do todo (e nem mesmo agora estamos separados). Mas agora, daquele homem se aproximou outro homem, querendo existir. E nos encontrando, pois não estávamos separados do todo, ele se revestiu de nós e acrescentou a si mesmo àquele homem, o que cada um de nós era então.

0 primeiro homem, que já existia no inteligível antes de nosso nascimento, é nossa alma, ligada a uma forma inteligível ${ }^{8}$. 0 outro homem é o composto formado pelo corpo e a imagem da alma, que,
2. Cf. BRANDÃ0, 2007b

3. III, 4,3 .

4. Ou seja, um corpo já preparado para se ligar a uma alma (IGAL, 1979, p. 329)

5. IGAL, op. cit., p. 324

6. Ibid., p. 324

7. Ibid.

8. Que pode ou não ser a forma do indivíduo. A questão ainda e controversa. Cf. HADOT, 1980; BLUMENTHAL 1996; OUSAGER, 2005. 
0 tema da consciência e da inconsciência aparece no nono capítulo da Enéada I, 4 em uma discussão sobre a felicidade. De acordo com Plotino,
Portanto, o nós é duplo: um que leva em conta a fera e outro que já está acima disso. A fera vivificada é o corpo, mas o verdadeiro homem é outro, o purificado destas coisas, que tem as virtudes da inteligência, aquelas que certamente se firmam na própria alma separada, separada e separável ainda estando aqui (En. I, 1, 10).

Plotino é claro: o ser humano é composto de sua parte animal e de sua alma, mas o homem verdadeiro é a alma, aquela que, mesmo estando aqui, pode-se separar das suas afecções do corpo. Portanto, o eu não é um foco de consciência, mas é a própria alma. É que o lemos I, 1, 7:

As coisas anteriores são nossas, mas nós (hemeís) somos o que existe daí para cima, assentado sobre o animal. Nada impede que a totalidade seja chamada de parte é, assim suponho, o homem verdadeiro; aquelas são leoninas e, no geral, feras variadas. Coincidindo o homem com a alma racional, quando raciocinamos, nós raciocinamos com os raciocínios que são atos da alma.

Esses textos indicam que o termo hemeís tem duas acepções: uma geral que engloba toda a estrutura humana e outra mais restrita, que designa a alma. Essa é a acepção principal. Na verdade, o primeiro sentido é utilizado nas Enéadas como derivado do segundo: nós também somos o composto de corpo e imagem da alma porque a alma o preside de cima. Assim, o composto só faz parte de nossa identidade enquanto ligado à alma.

Se nossa verdadeira identidade é a alma, os diversos estados de consciência são uma consequência, não a causa, das diferentes disposições da alma com relação ao que the é superior e inferior. Eles não são o eu, mas são condicionados por ele. Existem cinco níveis de consciência descritos nas Enéadas: a insconsciência, a consciência que se utiliza da imaginação, a consciência que não se utiliza da imaginação, a supraconsciência da alma unida ao Intelecto e a supraconsciência da alma ligada ao Um. a felicidade é a vida intelectiva, com a qual o verdadeiro sábio se identifica permanentemente (En. I, $1,4)$, ainda que esteja dormindo ou em coma (En. I, $4,9)$, pois o homem tem uma atividade intelectiva permanente, mesmo quando não está consciente disso. Para mostrar como isso é possível, no décimo capítulo do tratado, Plotino passa a explicar o funcionamento da consciência:

E parece que a apreensão (antilépsis) existe e acontece quando o pensamento e aquilo que está conforme o viver da alma que age retorna, como que rebatido de volta, como em um espelho, quando a superfície lisa e reluzente repousa (En. I, 4, 10).

Para se referir ao que nós chamamos de consciência, Plotino usava três palavras gregas distintias $^{9}$ : antilépsis, parakoloúthesis e sunaisthesis. A antilépsis é a apreensão tanto dos objetos sensiveis quanto dos inteligíveis pela imaginação. 0 termo parakoloúthesis significa a consciência humana, que vem acompanhada de pensamento ou imagem. Por sua vez, sunaísthesis, que indica uma relação da parte com o todo, do todo com a parte e da parte com a parte, exprime a unidade da consciência de algo que é composto de partes.

A passagem de I, 4 citada acima trata justamente da antilépsis. De acordo com o texto, ela ocorre quando o pensamento é refletido pela phantasía (a faculdade imaginativa), como em um espetho, quando sua superfície lisa e reluzente está em repouso. Aqui devemos fazer duas observações. Em primeiro lugar, Plotino fala especificamente do reflexo do pensamento, não mencionando a percepção sensivel, que aparece em outros textos. Essa omissão parece existir porque o texto trata especificamente da consciência das operações inteligíveis da alma. Em segundo lugar, como observa McGroarty (2006), Plotino parece pensar não tanto em uma supefície polida de um espelho, mas em um reflexo na água que só existe quando a água está em repouso. A comparação é especialmente oportuna porque, na 
passagem seguinte, o texto trata das circunstâncias nas quais esse reflexo não ocorre:

Como então, nessas circunstâncias, estando presente o espelho a imagem surge, mas, não estando presente ou não se encontrando no estado adequado, ainda assim está presente em ato aquilo cuja imagem existiria, assim também, no que diz respeito à alma, repousando aquilo em nós que é tal que manifesta as imagens do raciocínio discursivo e do intelecto, elas são vistas e como que conhecidas sensivelmente juntamente com o primeiro conhecimento de que o intelecto e o pensamento discursivo estão ativos Todavia, se isso é rompido pela perturbação da harmonia do corpo, 0 pensamento discursivo e o intelecto inteligem sem imagem e, assim, existe intelecção sem imaginação (En. I, 4, 10).

Assim como o reflexo na água é perturbado quando a água não está em repouso, a imaginação pode não ser produzida quando a harmonia do corpo é rompida. 0 texto não esclarece como seria possível romper a harmonia do corpo e os próprios comentadores se mostram confusos nesse ponto ${ }^{10}$. No entanto, como essa passagem aparece no contexto de uma discussão na qual Plotino investiga a felicidade do sábio que deixou de estar consciente por motivo de enfermidade ou por arte mágica (En. I, 4, 9), creio que a perturbação do corpo é justamente aquela que o faz entrar em coma. Nesse caso, a atividade intelectual continua, mas não é apreendida pela imaginação.

Assim, a inconsciência aparece como uma disposição fragmentada da totalidade do ser humano, na qual nem as sensações percebidas através do corpo, nem as intelecções realizadas pela potência da alma ligada ao mundo inteligível atingem a faculdade imaginativa. Não se trata, portanto, de uma falha nas atividades da alma, mas de uma falha de comunicação entre as diversas faculdades de uma alma ligada a um corpo.

Por sua vez, a consciência ordinária, do homem que vive e age no mundo sensível, é a percepção, por parte da faculdade imaginativa, dos reflexos da atividade da faculdade sensitiva e da intelectual que chegam até ela. A imaginação aparece, assim, como uma faculdade responsável pela integração interior do ser humano composto de alma e corpo. Encontramos idéias semelhantes em IV, 8, 8:

Pois nem tudo o que acontece alguma parte da alma nós conhecemos antes que chegue à alma inteira. Assim como também nós só conhecemos um desejo que permanece na faculdade apetitiva através o percebemos com a faculdade sensitiva interna ou com a discursiva ou com ambas (En. IV, 8, 8, 4-11).

Nessa passagem, a análise de Plotino se torna mais complexa e precisa: existe consciência em uma alma ligada a um corpo quando a intelecção, sensação ou afecção chega à alma inteira, ou seja, quando a atividade de uma potência superior ou inferior da alma é percebida por outra, intermediária. Isso pode acontecer de três modos: quando percebemos pela faculdade sensitiva interna (aisthetiké), noção derivada do sentido comum aristotélico que, nas palavras de Blumenthal (1971, p. 42), quase coincide com a faculdade imaginative; quando percebemos com a potência discursiva (dianoetiké); quando percebemos com ambas as potências.

Mas o que significam essas três possibilidades? Trata-se, ao meu ver, de três experiência distintas de consciência, todas elas, no entanto, familiares ao homem comum. Uma das possibilidades descritas por Plotino é a da consciência realizada somente pela faculdade sensitiva comum. Esse parece ser aquele estado de consciência em que percebemos alguma coisa, sem no entanto, raciocinarmos a esse respeito. Usando, como Plotino, o exemplo do desejo, essa primeira possibilidade parece ser aquela que acontece quando percebemos que desejamos alguma coisa, mas não refletimos acerca desse desejo. A outra possibilidade é a mais frequente: 0 estado de consciência que utiliza tanto a imaginação quanto a razão discursiva. É a consciência que existe quando temos uma imagem do pensamento, emoção ou sensação e, ao mesmo tempo, processamos seu significado. É o nosso pensamento a partir de imagens.

Por fim, Plotino aponta um outro estado mental, a consciência realizada através da razão discursiva. Trata-se de uma possibilidade difícil de ser compreendida, já que, como vimos em I, 4,
10. McGroarty, op. cit., p. 156: “0 que Plotino quer dizer exatamente pela perturbação da harmonia do corpo não é claro. Provavelmente, não é simplesmente o caso de quando nosso corpo interrompe o poder de imaginar, fazendo, assim, com que as imagens da alta imaginação sejam confundidas com as imagens da baixa" (0 que parece ser a posição de Blumenthal, 1971, p. 156). 
Plotino parecia sugerir que a consciência humana era sempre fruto da atividade da imaginação. No entanto, esse texto parece mostrar justamente que existem outros estados de consciência acessiveis a nossa experiência ordinária. Estamos aqui diante de uma espécie de consciência sem imagens, fundamentada exclusivamente na parte dianoética da alma. Minha hipótese é que esse pode ser o nível de consciência que, para ser distinguida dos demais estados mentais, foi chamado por Smith (1978) de quase-consciência $^{11}$. É o estado típico das ações mais elevadas, que requerem um nível maior de concentração. Plotino as descreve na continuação da já citada passagem de I, 4, 10:

Algum encontraria muitas belas atividades, tanto contemplações quanto ações, também quando estamos despertos, das quais não temos a consciência (to parakoloutheín) ${ }^{12}$. Pois não é necessário a quem está lendo ter consciência de estar lendo, sobretudo quando lê com intensidade; nem quem é corajoso, de estar sendo corajoso e de agir, na medida em que age, conforme a coragem. E outros milhares de exemplos; é que as tomadas de consciência podem fazer mais débeis as próprias atividades de que são conscientes, enquanto, estando sós, são então puras e mais agir e mais viver e, certamente. Certamente, estando o sábio nesse estado, o viver é mais intenso, pois não está difuso na sensação, mas está aquilo que é seu reunido em si mesmo.

A quase-consciência é, portanto, um nível mais elevado de consciência, comum durante as ações virtuosas e as práticas contemplativas mais intensas. Como Plotino observa, nesses casos, a autoconsciência da própria performance - que me parece ser justamente uma imagem da atividade realizada -, é um empecilho para a sua execução. Ao contrário da inconsciência, que é um estado de desagregação provocado por algum distúrbio físico, a quase-consciência é uma condição ainda mais integrada que a consciência ligada à imaginação: não existe aqui uma falha de comunicação entre as diversas potências, mas um repouso das potências inferiores para que as superiores possam realizar plenamente a sua atividade.
De acordo com Smith (1978, p. 298), Plotino parece atribuir um estado de quase-consciência à Alma do mundo em sua relação com o mundo sensível. Ao contrário das almas humanas individuais, que, pelo desejo de individualidade e apego ao sensível, acabaram se identificando com o mundo material, a Alma do mundo governa as realidades inferiores sem apegar-se a elas. É natural, portanto, que a sua consciência dessas realidades seja diferente da que existe na alma humana. Na verdade, já que em I, 2, 1 Plotino nos exorta a imitar a Alma do mundo através da virtude, podemos pensar que “nós devemos imitar o modo como ela (a Alma do mundo) governa o mundo sem ser distraída" (SMITH, 1978, P. 298). No entanto, essa identificação não é tão simples. Ainda que a Alma do mundo governe 0 universe sensível sem ser distraído por ele, dada sua ligação com o Intelecto e, por consequência, com o Um, ela possivelmente se encontra permanentemente em um estado de supra-consciência, não de quase-consciência.

De qualquer modo, é esse estado de quase-consciência que Plotino parece ter em mente em I, 2, 4, quando fala que a virtude resultante da conversão ao inteligível é "uma contemplação (théa) e uma impressão (túpos) do que foi visto impressa e em atividade, como a visão em relação ao que é visto", bem como da contemplação quieta, realizada pela alma reduzida à unidade depois dos extensos procedimentos dialéticos (En. I, 3, 4). Afinal, as "belas atividades" realizadas sem a contribuição da imaginação, aludidas em I, 4, 10 são tanto ações quanto contemplações. Interpretando os textos dessa forma, encontramos novas perspectivas de compreensão da experiência mística plotiniana, pois a quase-consciência me parece ser o primeiro nível de contemplação ${ }^{13}$, não ainda supra-racional, das realidades inteligíveis ${ }^{14}$. Pensando assim, estariamos mais perto de entender como acontecem as experiências supra-racionais e como podem ser alcançadas.

De qualquer maneira, nos estados de inconsciência, consciência e quase-consciência, o eu não é um estado mental, mas a alma a partir da qual os estados mentais surgem. Isso é claro no estado de inconsciência: interpretando o eu como o foco de consciência e pensando a inconsciência como um 
estado no qual esse foco não se encontra estruturado, deveriamos pensar que alguém que dorme ou está em coma não possui mais um eu?

A quase-consciência não é a experiência contemplativa mais elevada descrita nas Enéadas. De acordo com Plotino, quando a alma se purifica do apego ao mundo sensivel e, convertendo-se ao inteligível, é capaz de concentrar-se totalmente nas esferas superiores da realidade, ela pode se unir ao Intelecto e, em seguida, ao Um, experimentando níveis superiores de consciência que, longe de serem estados altamente emotivos e irracionais, como interpretaram alguns dos estudiosos dos séculos XVIII e XIX ${ }^{15}$, são modos superiores de conhecimento, no qual sujeito e objeto se encontram unificados.

Existem nas Enéadas dois níveis de supra-consciência: o estado de união da alma com o Intelecto e o estado de união com o Um ${ }^{16}$. A união da alma com o Intelecto ocorre quando a ela se desapega totalmente do sensível. Nesse caso, não há mais nada que a torne diferente de um intelecto e, assim, ela se torna capaz de se unir ao Intelecto ${ }^{17}$. Quando isso ocorre, a ela experimenta um nível de consciência superior, na qual não mais se vê como um ser humano (En. V, 3, 4), mas como o próprio o mundo inteligível. Não é fácil entender a natureza dessa experiência ${ }^{18}$, mas podemos apontar algumas de suas características ${ }^{19}$ :

1. Nesse estado, a alma experimenta-se como a totalidade do mundo inteligível, não que possua um conhecimento absoluto, no qual percebe todas as formas separadamente. A alma as percebe como uma visão da totalidade indistinta:

Verá, pois, uma inteligência, vendo não algo sensível, nem alguma destas coisas mortais, mas intuindo 0 eterno com o eterno - todas as coisas no inteligível -, tornando-se também um mundo inteligível e luminoso, iluminado pela verdade que procede do Bem, aquele que irradia a verdade a todos os inteligiveis (En. IV, $7,10,32-37)$.

2. É uma supra-consciência na qual o conhecimento não é exterior, mas uma espécie de autoconhecimento ${ }^{20}$, no qual a alma percebe o Intelecto tal como se percebe:
Mas aqueles que não vêem o todo consideram somente a impressão exterior. Já aos que estão totalmente como que embriagados e saturados de néctar, pois a beleza penetrou toda a sua alma, não thes pertence apenas se tornar contempladores, pois não existe mais, por um lado, aquele que contempla, exterior e, por outro, o contemplado, também exterior. Mas, aquele que vê com vista aguda tem em si mesmo o que é visto. $E$, tendo-o, na maioria das vezes desconhece que tem e olha como se fosse algo exterior, porque o vê como algo que é visto e porque quer ver. Tudo o que alguém olha como objeto de contemplação, olha como algo exterior. Mas é necessário transferir já a visão para si mesmo e ver como uma unidade, e ver como a si mesmo (V, 8, 10, 33-45).

\section{3. É uma visão intelectual sem imagens:}

Então, quando aquele que se prepara para a contemplação dele imagina grandeza, figura ou volume a respeito desta natureza, o Intelecto não se tornou o condutor da sua contemplação, pois não é natural ao Intelecto ver tais coisas, mas se trata de uma atividade da sensação e da opinião que segue a sensação (VI, 9, 3, 27-32).

4. Trata-se de uma experiência de beatitude que, além disso, não está sujeito ao erro, já que o sujeito não está separado do objeto. Esse é um ponto importante para compreendermos a relação de Plotino com o ceticismo antigo: é tendo em mente esse tipo de experiência que Plotino se sente tão confortável com os argumentos do ceticismo ${ }^{21}$, que ele cita em algumas passagens, nas Enéadas V, 3, $1^{22} \mathrm{e}$ V, 8, 1, por exemplo, sem se preocupar em refutá-los e, pelo contrário, considerando-os válidos na esfera limitada do conheciento sensível e dianotético.

5. É uma experiência inefável que Plotino equivale, em algumas passagens, a uma possessão divina:

Mas é necessário já transferir a visão para si mesmo, ver como uma unidade, e ver como a si mesmo. Como alguém que, possuído por algum deus, inspirado por Febo ou por alguma Musa, em si mesmo realizasse a visão do deus - se fosse capaz de ver o deus em si mesmo (V, 8, 10, 32-42).
15. Cf. BRANDÃO, 2007b, p. 152. 16. Cf. BRANDÃ0, 2007b. Narbonne (2011) acredita que Plotino desenvolveu gradualmente sua doutrina da união com o Intelecto a partir da polêmica com os gnósticos. No entanto, deve-se notar que já em tratados anteriores como IV, 8 e VI, 9 a doutrina já está presente, ainda que não plenamente explicitada. 17. Cf. BRANDÃO, 2007a. 18. Cf. WALLIS, op cit. 19. Retomo aqui as idéias de BRANDÃ0, 2008

20. Sobre o autoconhecimento do Intelecto, cf. CRYSTAL, 1998 21. Cf. MARSOLA, 2007. 22. Cf. CRYSTAL, 1998. 
6. A alma ligada ao Intelecto não mais se experimenta como um indivíduo encarnado, mas como a própria totalidade inteligível. Para Plotino, nossa identidade não é necessariamente ligada a uma individualidade. Na verdade, como nota O'Daly (1973, p. 57), a individualidade da alma é uma diminuição de sua identidade. É que, originalmente, a alma não está separada das outras almas ou do mundo inteligível. É com seu desejo de ser de si mesma $^{23}$ e sua ligação com o corpo que surge a separação que, no entanto, não deixa de ser ilusória: a parte superior da alma, diz-nos Plotino em IV, 8,8 , nunca se afastou do mundo inteligivel ${ }^{24}$. A experiência de união com o Intelecto é, portanto, a consciência de uma unidade que nunca deixou de existir, ao menos parcialmente.

No entanto, pensando que, nesse estado superior de consciência, experimentamos nosso eu como a totalidade inteligível, podemos ser tentados a retomar a teoria do eu como um foco de consciência. Mas isso não é necessário: nos percebemos como um mundo inteligível porque nossa alma uniu-se ao Intelecto.

Superior a união ao Intelecto é a experiência da união mística com o Um. Plotino diz que não se pode conhecê-lo nem pela ciência, nem pela intelecção, como no caso dos outros inteligíveis, mas através de uma presença superior à ciência. Tal contemplação é chamada, em alguns momentos, de visão. Mas trata- se de outra forma de ver: "êxtase e simplificação e um dom de si, desejo de contato, repouso e consideração de uma harmonização" (En. VI, 9, 22-25).

Por ser uma experiência inefável, não é fácil compreendê-la. 0 próprio Plotino, consciente da insuficiência da linguagem, emprega imagens que oferecem apenas aproximações e que, algumas vezes, parecem ser contraditórias. Na passagem de VI, 9, 11 citada acima, por exemplo, Plotino fala, ao mesmo tempo, de ékstasis e stásis, mas como a experiência mística do Um pode ser ao mesmo tempo saída de si e permanência?

Apesar disso, também é possível enumerar algumas características dessa experiência ${ }^{25}$. Em primeiro lugar, assim como na união com o Intelecto, Plotino a descreve como arrebatamento e possessão.
Mas não se trata de um estado de emoção intensa, mas de uma experiência de permanência total e completa unidade, na qual não apenas o sensível, mas também o inteligível é suprimido:

Mas como que arrebatado ou possuído tranqüilamente na solidão e vindo a estar em uma condição inabalável, não se apartando com nenhuma parte de sua essência, nem se virando sobre si mesmo, está todo em repouso, como se viesse a ser permanência (En. VI, 9, 11, 12-16).

A união com o Um implica um estado de unidade absoluta ${ }^{26}$. Portanto, pressupõe uma forma de identidade que está além da autoconsciência. Aquele que se encontra nesse estado não se experimenta mais como homem, nem mesmo como ser. Tudo o que existe é unidade e permanência:

E nem sente o corpo, no qual está, nem diz que é alguma outra coisa: nem homem, nem animal, nem ente, nem o todo - pois a contemplação dessas coisas seria de algum modo inconstante - e nem tem tempo livre para se voltar para elas, nem quer. Mas, tendo buscado aquele, quando ele está presente, vai ao seu encontro e o vê no lugar de si mesma. E quem é ela que o vê, nem isso tem tempo livre de ver (En. VI, 7, 34, 16-21).

Apesar disso, como o Um é o objeto último de desejo de todas as coisas, e aquele a quem se dirige o verdadeiro amor da alma, essa união é a coisa mais valiosa:

Ali, certamente, não o trocaria nem por todas as coisas, nem se the oferecessem todo o céu, pois já não existe nada mais precioso e melhor que o bem. Com efeito, nem poderia correr mais para cima, as outras coisas todas estando abaixo, ainda que estejam no alto. Assim então, pode julgar belamente e conhecer que este é o que desejava e afirmar que não há nada mais excelente que ele (En. VI, 7, 34, 21-27).

Para sintetizar, a união mística com o Um é um estado de unidade pura, na qual toda a alteridade foi suprimida. Portanto, durante a experiência, a alma não pensa em nada e não se volta nem para 
os objetos sensíveis, nem para os inteligíveis, mas, transcendendo todos eles, une-se ao Absoluto e entra em um estado sumamente agradável, não porque sinta alguma emoção, mas porque alcança o seu bem último e supremo. 0 estado de união é uma experiência contemplativa, mas é diferente de todas as formas de contemplação: não possui um objeto, pois toda a dualidade foi superada. Tudo que existe é a intuição da unidade pura.

Não se trata, portanto, de uma descida ao irracional, mas da contemplação do fundamento último da realidade. Mas, pela própria natureza do Um, essa não é uma forma de conhecimento na qual um sujeito conhece um objeto. A alma não vê o Um como objeto, mas, ao ficar completamente quieta, torna-se uma só coisa com ele. Então, tudo o que existe é uma supraconsciência, semelhante à supraconsciência do Um, que é superior a todo tipo de conhecimento e pensamento. Assim, nessa união, o eu sofre profundas transformações, ao se tornar identidade pura. Mas não deixa de ser a alma. Lendo os textos das Enéadas a esse respeito, é possivel perceber os limites dessa união: a alma suprime a alteridade aquietando as suas potências; quando ela é una, nada se move nela, nem as paixões, nem os discursos, nem as intelecções (En. VI, 9, 11, 15 e é essa quietude absoluta a sua semelhança com o Um. No entanto, esse não é um estado permanente. As experiências de união são passageiras e, portanto, a alma inevitavelmente volta à esfera da alteridade. Portanto, ainda que durante a experiência, a ela esteja unida ao Um e, de algum modo, ambos sejam um só, ela ainda é, potencialmente, uma alma.

Não se trata, portanto, de um eu que se tranforma no Um, mas da alma que se liga ao Um. Assim, a teoria do eu móvel, ainda que tenha o mérito de ter chamado a atenção para as transformações que 0 homem sofre em sua identidade durante o processo de ascensão filosófica, deve se tornar mais precisa. 0 eu não é uma entidade autônoma e separada das realidades substanciais, mas é a própria alma que, ao se dedicar à filosofia, passa por modificações que implicam em estados de consciência superiores. Fica claro assim que a jornada de ascensão apresentada por Plotino é, antes de tudo, uma prática de cuidado da alma e um caminho para a sua transformação ${ }^{27}$.

\section{BIBLIOGRAFIA}

BLUMENTHAL, H. On Soul and Intellect. In: GERSON, L. The Cambridge Companion to Plotinus. Cambridge: Cambridge University Press, 1996, p. 82-104.

Plotinus' Psychology: his doctrines of the embodied soul. The Hague: Martinus Nijhoff, 1971.

BRANDÃO, B. A contemplação mística do Um em Plotino. Sapere Audere, n. 2, 2010. Disponível em http://periodicos. pucminas.br/index.php/SapereAude/article/view/1297

A união da alma e do Intelecto na Filosofia de Plotino. Kriterion, n. 116, 2007b, p. 481-491. Disponivel em http://www.scielo.br/pdf/kr/v48n116/ a1348116.pdf

Só em direção ao só: considerações sobre a mística de Plotino. Horizonte, v. 6, 2007b p. 150160. Disponível em: http://periodicos.pucminas.br/index. php/horizonte/article/viewArticle/401

BREHIER, E. La Philosophie de Plotin. Paris: J. Vrin, 1961.

CRYSTAL, I. Plotinus on the structure of self-intellection. Phronesis, vol. 43, n. 3, 1998, p. 264-286.

DODDS, E. The Parmenides of Plato and the origin of the neoplatonic One. The Classical Quartely, 22, 1928, p. 129-142.

Tradition and personal achievement in the philosophy of Plotinus. Journal of Roman Studies, 50, 1960, p. 1-7.

HADOT, P. Les Niveaux de Conscience dans Les États Mystiques Selon Plotin. In: Journal de Psychologie, n. 2-3, 1980 , p. 243-265.

Plotin ou la simplicité du regard. Paris: Éditions Gallimard, 1997.

IGAL, J. Aristotele y la evolución de la antropologia de Plotino. Pensiamento 35, 1979, p. 315-346.

MARSOLA, M. Plotino e o ceticismo. Dois Pontos, vol. 4 , n. 2, 2007.

MCGROARTY, K. Plotinus on Eudaimonia: a commentary on Ennead I, 4. 0xford: Oxford University Press, 2006.

O'DALY, G. Plotinus Philosophy of the Self. Shannon, 1973.

OUSAGER, A. Plotinus on freedom, selfhood and politics. Aarhus: Aarhus University Press, 2005.

SMITH, A. Unconsciousness and quasiconsciousness in Plotinus. Phronesis, 23, 1978, p. 292-301.

WALLIS, R. Nous as Experience. In: HARRIS, B. (editor). The Significance of Neoplatonism. Virginia: International Society for Neoplatonic Studies, 1976, p. 121-143.

WARREN, E. Consciousness in Plotinus. Phronesis, 9, 1964, p. 83-97.

WILBERDING, J. Automatic Action in Plotinus. Oxford Studies in Ancient Philosophy, 34, 2008, p. 443-477.

Artigo recebido em janeiro de 2012 e aprovado em fevereiro de 2012.
27. Devemos ser claros nesse ponto: essa transformação da alma não implica em torná-la diferente do que ela é em sua natureza, mas descobri-la em sua forma original, ligada ao Intelecto e ao Um e desapegada do sensível. Podemos falar em transformação, portanto, pensando-a enquanto encarnada, mas não encarando-a a partir de sua essência. 